\title{
G. CANGUILHEM Y EL CULTO DE LOS HECHOS; ESBOZOS DE UNA FILOSOFÍA DE LA AUTONOMÍA HUMANA (1926-1939) ${ }^{1}$
}

\author{
Alejandro Bilbao \\ Departamento de Humanidades y Artes \\ Universidad de los Lagos \\ manuel.bilbao@ulagos.cl
}

La philosophie a une autre tache, qu'elle élude depuis un siècle : c'est la compréhension et la libération de l'individu.

G.Canguilhem

(La fin d'une parade philosophique: le bergsonisme, 1929)

\section{RESUMEN / ABSTRACT}

El presente artículo analiza el periodo de conformación de la filosofía de Georges Canguilhem (1926-1939). Se concentra en la elaboración temprana de sus ideas relativas a la teoría del valor y de la autonomía de la acción humana. Dos aspectos de esta filosofía son tomados en consideración. En primer lugar, el vinculo que mantiene el entendimiento con los hechos que forman parte de la realidad, observando la incidencia de esta filosofía del valor y de la acción en el dominio de tres disciplinas pertenecientes a las ciencias sociales (psicología, sociología, historia). Un segundo momento del texto analiza el espacio asignado por estas elaboraciones al psicoanálisis, teoría que Canguilhem asocia a los fundamentos de la dimensión política y ética de esta filosofía.

Palabras Clave: axiología, filosofía de la acción, gnoseología, historia de la ciencia, ontología, psicoanálisis.

\section{G. CANGUILHEM AND FACTS WORSHIPPING; DRAFTS OF A HUMAN AUTONOMY PHILOSOPHY (1926-1939)}

This article analyses the formation period of Georges Canguilhem's philosophy. It focuses on the early development of his ideas related to the value and human action autonomy theory. Two aspects of this philosophy are considered. First, the relationship beween understanding and the "facts that are part of reality, observing the impact of this value and action philosophy on the domain of three social science disciplines (psychology, sociology and history). Second, this text analyses the assigned space by these elaborations

1 Esta publicación se enmarca en el contexto de una investigación más vasta titulada: "Filosofía y medicina en G. Canguilhem: axiología, ontología y política de lo viviente". Mis agradecimientos a ANID/Programa Fondecyt-regular/ proyecto Cod: 1210534. 
to psychoanalysis, a theory that Canguilhem relates to the foundations of the political and ethical dimension of this philosophy.

KEYWORDS: axiology, action philosophy, gnoseology, science history, ontology, psychoanalysis.

\section{Introducción}

R⿴囗十 De un modo general, las presentaciones referidas a la obra de G. Canguilhem acentúan la faceta histórico-epistemológica de sus preocupaciones relativas a las ciencias de la vida. Se agrega a estas exposiciones, la orientación antipositivista de sus investigaciones, su figura de continuador de las teorizaciones de Gastón Bachelard para una forma francesa de considerar la historia de la ciencia (Lecourt 2008). Si bien muchos de sus textos despliegan una considerable erudición en ámbitos de la teoría celular, de la embriología y de la fisiología del siglo XIX, sus inquietudes desbordan extensamente tal margen investigativo (Braunstein 2010: 10). Tempranamente, las conceptualizaciones desarrolladas por Canguilhem esbozan un interés que se extiende por fuera de los márgenes investigativos de la historia epistemológica, abarcando un panorama de importantes problemas éticos, morales y ontológicos. En un primer tiempo, retomando algunos de los textos producidos por Canguilhem durante el periodo de 1926-1939, el presente texto intenta mostrar el lugar que ocupan estos problemas en la organización de su filosofía del conocimiento. Aspectos que concentran una singular delimitación para el campo conceptual que la psicología, la sociología y la historia estructuran en sus respectivas consideraciones de la individualidad humana. En un segundo tiempo, se analiza el lugar que cabe para el psicoanálisis frente a un tipo de filosofía que se inclina a abordar el problema de la autonomía y la acción. Ambos tiempos son expuestos como elementos constituyentes de la antesala filosófica que prepara la organización de un pensamiento referido a la vida y las normas. El presente texto ilustra el itinerario de esa construcción filosófica.

\section{La psicología, la sociología y la historia; el servilismo ante los hechos}

Durante el periodo inicial de la filosofía de Canguilhem (1926-1939), el problema planteado por la psicología, por la historia y por la sociología es expuesto en razón del entendimiento que es asignado a la relación que los hechos mantienen con la actividad del juicio y la realidad. Al interior de la filosofía de Canguilhem, esta relación no comprende la sumisión o adoración ante lo dado, como lo consigna la expresión "adorateurs des faits", tomada del texto de Alain "Laches penseurs" (1960: 549-705). En el intento por organizar una definición de la individualidad humana, las críticas dirigidas a la psicología alcanzan un vasto panorama conceptual, observable en textos posteriores a este inicial periodo (Canguilhem 2011: 365-381). Estas detracciones, permiten erigir un pensar relativo a la verdadera tarea que debe guiar a la filosofía, que, para estos años, es aquella que reflexiona en torno de la "liberación" del individuo. 
El 20 de abril de 1929, en un texto titulado "La fin d'une parade philosophique: le bergsonisme" (Canguilhem 2011: 221-228), la psicología es la primera de estas tres disciplinas que se vuelve objeto de crítica. Lo que es criticado en este texto, es la manera que ella admite para comprender la realidad de los hechos mentales. Estos son considerados a partir de la simple objetivación de la actividad del pensamiento, volviéndolos meros objetos o cosas. Para Canguilhem, estos hechos son inseparables de lo que hay de único y especifico en el hombre, como es su capacidad de obrar acorde al pensar. Para el joven Canguilhem, la actividad del juicio no puede ser reductible a las objetivaciones que sistemáticamente instaura el proceder científico. Si el pensar no es simple percepción de los hechos, traducción del modo de acontecer de los fenómenos, es porque como actividad expresa todo lo que deja de ser en los hechos. Por medio del pensar, el hombre construye formas de entendimiento dirigidas al mundo, acciones de valor, instaura las normas que son necesarias al ejercicio del derecho y la moral. Sirviéndose de una metáfora pronominal, la expresión "pensar en tercera persona", emerge en los primeros pasajes del texto de 1929, como la manifestación de un pensar que se toma asimismo como cosa, desarraigado de los motivos de su proceder concreto.

Canguilhem toma esta expresión de Politzer para resaltar la forma que el pensamiento posee para negar la simple adaptación ante lo "concreto". La idea de un "pensar en tercera persona" se vincula de este modo a una actividad deliberativa de carácter impersonal, simple acto analítico del juicio. Los intereses del hombre frente al conocimiento de lo real, implican una valorización de este acto de conocimiento, aspecto que devela la relevancia que Canguilhem asigna a la individualidad humana. Esta es expresión del rechazo a la objetivación de la actividad del pensamiento, manifestación de todo aquello que se actualiza en el pensar cuando este es vinculado al tiempo de una subjetividad primera (inseparable del yo-sujeto). Esta forma de acentuar formas pronominales divergentes para evidenciar lo que es esencial en la experiencia del juicio y del valor es equivalente a la interrogación que filosóficamente habita en las relaciones que el organismo mantiene con la vida. Lo característico de esa relación, es el trabajo de valorización que el pensar actualiza en el conocimiento de su entorno.

En el contexto de los análisis y comentarios de este breve texto de 1929, Canguilhem expresa el inconformismo que todo teórico preocupado por la liberación del individuo debería considerar frente a la psicología postulada por Bergson (2009). La psicología de Bergson, como los métodos de la psicología clásica, parten de un conglomerado de enunciados que consideran los hechos psicológicos como realidades absolutas. Tal visualización, supone la admisión de supuestos generales que organizan y consideran los hechos mentales como cosas. En la atención concedida por este texto a la disciplina psicológica, las argumentaciones críticas se construyen y sostienen de las ideas de Politzer. Para el autor de la Crítica de los fundamentos de la psicología (1968), la historia que esta disciplina devela desde fines del siglo XIX no es expresión de la constitución progresiva de su organización conceptual, siendo antes que nada, la evidencia de su disolución. De algún modo, la historia de este movimiento psicológico contemporáneo, devela la disolución del mito de la objetividad presente en los estudios relativos al hombre. Para Politzer, la ciencia psicológica debe escribirse en "primera persona", su verdadera trasformación solo puede acontecer en la medida en 
que los hechos que indaga sean asociados a un tipo de subjetividad que se expresa en primera persona (1968: 42-43). La crítica formulada a la psicología es un rechazo a sus métodos, a sus principios, a la "credibilidad" extrema que deposita en los hechos que son aportados por la experiencia. Asentada en esta credibilidad, la psicología y sus procedimientos consideran al espíritu como un simple hecho, estudiándolo como un universo divisible. El espíritu se convierte en "un pequeño universo separable y observable, como los aparatos, haciendo de él una cosa, enterrándolo como espíritu" (Canguilhem 2011, p. 224).

Empero, la crítica disciplinaria dirigida a la psicología se sostiene de un continente de análisis más vasto. Las referencias filosóficas son buscadas en Kant (Canguilhem 2011: 177-180), y en la escuela neokantiana del análisis reflexivo inaugurada en Francia por Canguilhem (2011, 228-239). Desde estos autores, se construye el lugar que filosóficamente se desea asignar a la individualidad humana, para una filosofía que es concebida como una Werphilosophie. La lectura de la Critica de la facultad de juzgar de Kant (2000), contribuye a sostener la diferenciación entre hecho (fait) y valor (valeur). Esta diferenciación apunta a desarrollar una crítica relativa a la legitimidad del conocimiento, revelando la problemática que una teoría del valor representa para el conocimiento de los objetos. Aun si estos elementos de crítica se apoyan inicialmente en elaboraciones de carácter gnoseológico, referidas al cómo y el por qué del conocer, estos aspectos del análisis retornan sobre los prejuicios ontológicos que dan prioridad al orden de los hechos y de lo dado. Tempranamente, G. Canguilhem se detiene sobre estos problemas para mostrar que no puede existir una relación con el mundo fenomenal que no sea ipso facto, una llamada a polarizarlo en valor. Es en este punto donde se encuentran las dicotomías establecidas por Canguilhem en torno de la "actividad sintética" y la "actividad analítica" del pensar. Como se observa, la psicología no es solamente considerada en razón de los a priori que establece en el conocimiento de los hechos mentales. Esta disciplina muestra el ámbito esencial de los problemas axiológicos y ontológicos que deben ser considerados en el conocimiento de las propiedades de organización del "viviente humano".

La psicología debe ilustrar los problemas que el hombre mantiene con la vida, con su medio, que delinean para Canguilhem, una representación relativa a la evolución humana. Puede considerarse de este modo, que, si se toman en cuenta las distintas facetas de evolución del hombre, es factible ver esta evolución concentrada en el encuentro entre el arte y la ciencia (actividad sintética vs. actividad analítica). Entre ciencia y arte se anuda el tejido empírico de esta evolución, el valor limitativo que la ciencia mantiene en su relación con la creación humana. Canguilhem señala:

La vida es la primera forma de esta actividad sintética, de la cual la técnica y el arte, constituyen en la humanidad su ejercicio más o menos puro. Si el "juicio de necesidad" renvía a la unificación por el trabajo del análisis, es decir por el trabajo de la ciencia, esta es "impotente para dar cuenta de la actividad en su totalidad", porque se le escapa sin cesar otra rama de la experiencia humana, que sin embargo la nutre, esta actividad sintética que unifica la experiencia "según el juicio del poder y del valor" (Canguilhem 2011: 755). 
En concordancia con la lectura de Kant, útil a los efectos de diferenciar las categorías del valor y de los hechos, el trabajo de la ciencia es visto como una actividad infértil para resaltar la originalidad de la experiencia humana. Originalidad que se expresa en las distintas funciones que cumple en el hombre la actividad sintética. Esta tendría por objetivo, unificar la experiencia según el dinamismo del juicio y el funcionamiento de una teoría del valor. Toda acción de conocer implica la valorización de lo conocido, su resultado es el ingreso en una red de valorizaciones que quedan supeditadas a la individualidad que las produce. Esta acción es considerada de manera temprana una relación, donde la noción de medio destaca la faceta creadora de lo viviente. La génesis de esta individualidad "indivisible" comienza para Canguilhem en el acto perceptivo, principio inicial de un estado irreflexivo. La percepción solo integra originariamente nuestros deseos, al modo de un "juicio de existencia," desfigurado por las urgencias que aporta el interés de los deseos. En este punto, se ubica la actividad sintética del pensamiento, originariamente juicio de valor, inicio de una relación de valía con el mundo fenomenal. Para Canguilhem, una ejemplificación de esta actividad sintética es la acción ejecutada por la técnica, que reproduce en un grado más elevado este acto perceptivo espontáneo que se erige en las relaciones con el medio. La síntesis realizada por la actividad técnica es por ello la prolongación del instinto y de la vida. La actividad técnica no es nunca la simple prolongación del conocimiento objetivo, como es admitido por la filosofía positivista. Esta actividad es la expresión de un poder original y creador, que ubica en un nuevo contexto las condiciones de acceso a la verdad del conocimiento. La preocupación por las relaciones entre la actividad sintética y analítica del pensamiento se esboza en las inquietudes que Canguilhem mantiene por la obra de Descartes, sobre quien escribe en 1937, un interesante trabajo relativo al problema de la técnica (2011: 490-498).

La filosofía de la autonomía humana ubica una visualización referida a la actividad sintética como un modo de reacción ante la sumisión a los hechos, acercando la deriva del conocimiento a las acciones de ficción y creación que recaen sobre los objetos y el mundo. Es en esta ficción que se inserta todo aquello que se da en llamar mundo vital, histórico y social. La forma de dinamizar estas hipótesis a lo largo del itinerario filosófico de Canguilhem conduce a apreciar de un modo distinto la lectura de textos posteriores de su obra, tales como; Machine et organisme y Le vivant et son milieu (Canguilhem 1992). Así, en lo referido al universo en el cual el hombre ocupa un lugar, la noción de valor evidencia que nada es necesario. De allí una visión en germen referida a los interjuegos de "lo posible," al riesgo, a los problemas que la vida le plantea al hombre. La actividad sintética enseña que la vida es siempre un fenómeno anterior que nos fuerza a la actividad del juicio, del pensar, a la valorización de los objetos. Este tipo de actividad, muestra que primero hemos vivido, y luego pensado, o que hemos pensado para vivir mejor. Señalar que el viviente humano ha vivido antes de pensar, implica considerar las posibilidades del error y del riesgo. Evento fundamental en la historia de las ideas filosóficas según Foucault:

Sin duda, se toca aquí uno de los eventos fundamentales de la historia de la filosofía. ¿Es acaso que toda la teoría del sujeto debería ser reformulada desde 
que el conocimiento antes que abrirse a la verdad del mundo, se arraiga en los errores de la vida? (Foucault 2011: Xxx)

La comprensión que para estos años Canguilhem expresa respecto de la psicología, de la historia y de la sociología no puede percibirse si no es refiriéndola al cuerpo mayor de estos análisis. El trabajo de la actividad analítica y la actividad sintética se encuentra evidentemente en la base de las preocupaciones referidas a la historia y la ciencia. Al punto que ambas deben volverse la ejemplificación de la actividad creadora de la conciencia humana. Aspecto, este último, que considera a los "historiadores del alma":

Si pueden, imaginen un psicólogo. Es un historiador del alma, para quien pensar no es más que saber lo que se piensa. Esta fría luz por medio de la cual se ilumina, no produce ni cambia nada. Cuando es necesario actuar, él describe; cuando es necesario desear, él busca prever (Alain 1960: 645-646).

La psicología, con sus métodos y procedimientos, no es criticada desde un punto de vista estrictamente epistemológico. La crítica que le es dirigida se centra en los aspectos éticos del conocimiento que ella propicia. La dimensión de lo cognoscible no puede en razón de ello distanciarse de la dimensión ética, conduciendo finalmente a una interrogación ontológica que insiste sobre el carácter de la individualidad que emerge en este tipo de conocimiento. En la articulación de variables de orden gnoseológico, axiológico y ontológico, la psicología puede ser pensada como una disciplina que en su variante comportamental y/o reflexológica vuelve al hombre un simple objeto, mecanizando sus actos y acciones. Esta situación de la mecanización de la conducta humana, ya había sido considerada por Canguilhem a propósito de los análisis de Alain sobre la guerra, donde la vertiente antimilitarista se constituye en uno de los modos de evitación de la mecánica de los actos. El cometido bélico despoja al hombre de su humanidad, considerando un instrumento. La guerra, así como toda disciplina que tome a los hechos como cosas, se convierte en la glorificación de los hechos, y si es solo la fuerza de los hechos lo que cuenta en lo relativo al hombre, expresiones como valor, derecho y justicia se tornan irrisorias. Para Canguilhem, la crítica tempranamente iniciada a propósito del militarismo, se extiende de un modo posterior, al rechazo radical de la explotación capitalista.

La historia es otra de las disciplinas que no considera el orden de la vida. En este sentido, no es posible aceptar como "datos" los pretendidos hechos históricos construidos por el historiador. Es finalmente del historiador, de sus lecturas y análisis, de quien se trata cuando es preciso establecer quién establece el orden de los hechos. En relación con la historia, estos análisis prefiguran las distancias que Canguilhem toma frente al marxismo. El marxismo prohíbe la instauración de interrogantes referidas al valor de las elecciones posibles ante los hechos, ocupando un lugar intermediario entre la historia y la sociología. En lo relativo al marxismo, es sobre la teoría de la ideología que las críticas se ordenan. La importancia de la norma y de los valores es destacada frente a una representación de los hechos sociales como cosas. 
Si llamamos ideología a todo sistema de juicios teóricos o prácticos, buscando las condiciones de su existencia en la infraestructura social, en lugar de buscarlas en sus condiciones de valor en una exigencia normativa interna, ¿qué medio se poseería para discernir lo ilusorio de lo válido? ¿Cómo se puede reconocer que la teoría de la ideología no es también una ideología? Los señalamientos críticos de Aron concernientes a la posición de Marx, la de Mannheim y la de Durkheim (puesto que hay en él una teoría sociológica de las categorías), son al respecto, importantes (Canguilhem 2011: 489).

La sociología es expuesta por la vía del dogmatismo que Canguilhem cree ver en las ideas de Durkheim. La Escuela sociológica francesa es definida de este modo como una "sociología pura", inclinada exclusivamente al análisis del mundo de los hechos. La pretensión de solo considerar este tipo de mundo, elimina la consideración de los valores, bajo la consigna de tratar los hechos sociales como cosas. Si es el valor de las cosas el que se ve eliminado mediante este tipo de consideración, es la categoría del pensar la que se ve descartada. El "valor" es sustituido por una realidad presuntamente aceptada en sí, y que el análisis termina substituyendo por el valor. Empero, las críticas dirigidas a la sociología consideran ciertas figuras que actúan como enclaves de excepción al interior de los problemas abiertos por la noción de valor. Estas personalidades son para Canguilhem, Célestin Bouglé y Maurice Halbwachs, ambos abiertamente distanciados de las ideas de Durkhiem. Tanto Bouglé como Halbwachs alojan en un sitio importante de sus reflexiones la exigencia impuesta por la dinámica de los valores. En 1931, G. Canguilhem destacará la importancia del texto de Halbwachs sobre Las causas del suicidio:

M. Halbwachs conduce su análisis a resultados cuya inesperada importancia no debe pasar desapercibida. Sus conclusiones para quien desee convenirlo, debilitan las pretensiones del dogmatismo sociológico que Durkheim introdujo sin matices en la escena filosófica (2011: 380).

Para Canguilhem, Halbwachs es uno de los pocos sociólogos franceses que supo preservar las exigencias de los valores, evitando la tentación de "tratar al hombre como un mecanismo" (Halbwachs 1930). Frente al dogmatismo de la tradición sociológica francesa que va de Comte a Durkheim, Canguilhem optará por la lectura de Max Weber para destacar los lazos que unen al individuo con la sociedad, preservando la importancia de la individualidad humana.

Durkheim tiene por centro la antinomia del individuo y del grupo; la disolución amenaza la sociedad presente y es necesario restaurar una disciplina, una moral colectiva...Al contario, la obra de Weber, y el trabajo de gran parte de los sociólogos alemanes, apunta en primer lugar a la singularidad histórica de nuestra civilización occidental, a saber, la racionalidad. No se trata en lo sucesivo de reestablecer una disciplina sino una comunidad: contra la burocracia y el orden abstracto, no contra la anarquía. Conceptos fundamentales, perspectivas históricas, métodos de análisis, dependen ampliamente de este dato inicial (2011: 488). 
Desde esta visión referida al lugar ocupado por la psicología, por la historia y la sociología, se constituye un trazo intelectual relevante para pensar la idea de individuo. Para estos primeros textos de juventud, como para aquellos escritos con anterioridad a 1944, dicha noción de individualidad es trabajada y tematizada al amparo de una idea de "indivisibilidad" de la experiencia de lo viviente. La delimitación de esta noción recibe para estos años un tratamiento que la vuelve inseparable de la noción de valor y de norma, acciones que destacan la presencia de un "absoluto subjetivo" necesario de ser considerado en todo intento de representación del individuo. Todo aquello que pueda ser pensado en tanto presencia de individualidad, obedece a principios que, en su acción, individualizan la vida humana. La vida y su individuación son consideradas en un trabajo que no puede prescindir de la experiencia del valor, del sentido y de la norma. Ejecuciones que hacen de la vida una experiencia anterior sometida a los actos de creación que el hombre organiza para conjurar la violencia que ella porta como indiferencia fundadora.

Para Canguilhem, los motivos que dinamizan la vida en tanto principios rectores de organización, se hallan en el propio organismo, distanciándose de este modo de una visión relativa a la vida fundada en elementos metafísicos y/o trascendentales. La vida es expresión de todo ser viviente, sometiéndolo a exigencias de individuación y de organización que expresan en mayor o menor grado la forma que ese organismo posee para relacionarse con su medio. Y de establecer de ese modo, las normas y sentidos que le son necesarios para la preservación de su existencia. La vida, el individuo, y todo aquello que permite lo que se individualiza en una vida, no expresa una naturaleza ya acabada, pues se trata de modos de individuación que no se identifican a lo finalmente individualizado. Se trata de un tipo de individuación entendida "como proceso y no como principio" (Simondon 2005: 31-32), que erosiona toda idea de individuo como una entidad en sí. La comprensión del tipo de trabajo que esta individuación compromete, se torna imposible sin la admisión de la pérdida de toda significación originaria o primera. Si a lo anterior se agregan las tesis relativas al medio circundante, se emplaza una concepción de individuo que antes de exponerlo como un centro de referencia, lo vuelve relación. Este terreno de problemas es teorizado de manera posterior en las indagaciones históricas que Canguilhem desarrolla a propósito del preformismo y la epigénesis (Canguilhem 1962). Indagaciones que evidencian que, en lo relativo a la vida humana, es siempre el organismo el que organiza sus modos de habitación. Modos que son igualmente la expresión de la autonomía de lo viviente. Esta autonomía de formas y creaciones vitales no se reduce jamás a modalidades de adaptación a un medio circundante, por cuanto ella es la expresión de las ficciones que el trabajo del sentido inserta sobre ese medio, volviéndolo posible y finalmente humano. Así lo deja entrever el texto redactado en 1936 a propósito del problema de la técnica en Descartes.

Empero, ciertos aspectos concebidos para comprender la situación filosóficamente abierta por la experiencia humana, y la consiguiente definición de individuo, son modificados de su versión original al interior de esta filosofía de la autonomía y de la acción. Luego de 1943, y de las clásicas tesis sobre Lo normal y lo patológico (Canguilhem 1966), el dominio óntico inicial que Canguilhem comprende para tratar el problema de la individualidad humana, se desplaza al análisis de las variantes 
éticas. La noción de individuo comienza a ser pensada en la relación que conforman los aspectos ontológicos y axiológicos. Desde estas proposiciones, relativas al hombre como un "núcleo subjetivo indivisible," la noción de individuo se erige como uno de los polos centrales de la experiencia humana, junto a la universalidad del hecho y de la experiencia. La noción de individuo se instituye como una forma de oposición, un "absoluto de lo subjetivo", frente a un real representado por los hechos universales de la naturaleza. Un "absoluto de lo real", que representa para el hombre, una única forma de representación del mundo y de los objetos. Esta oposición, continúa las elaboraciones kantianas referidas a la imaginación humana, extendiéndose a las oposiciones establecidas por R. Allendy respecto de la medicina de las enfermedades (disease) y del enfermo (illness). El individuo es la expresión de la relación que se organiza entre su condición presubjetiva y lo "absoluto de lo real".

Estas tesis serán sometidas a importantes modificaciones a partir de 1944, cuando los hallazgos de Oswald Avery (1944: 137-158), relativos a la biología molecular, indiquen que la substancia transformante del streptococcus pneumoniae, se encuentra constituida por $\mathrm{ADN}$ (ácido desoxirribonucleico). El individuo podría en consecuencia ser divisible, conduciendo a Canguilhem a reconsiderar la idea de individuo como una entidad indivisible. Los nuevos descubrimientos sobre la herencia parecen asegurar el triunfo de lo "discreto" sobre lo continuo, la conquista de la multiplicidad aleatoria sobre la unidad substancial del sentido. En 1977, el lugar de esta individualidad totalizante es considerado a partir de un importante desplazamiento conceptual, que releva la unidad substancial a la expresión de una coexistencia.

Entre los cultivos de bacterias por una parte, y los biólogos que observan sus vidas en laboratorio por otra parte, se intercalan todas las formas vivientes a las cuales el orden de la vida y el filtro de la selección han impuesto la existencia. Estos vivientes, viven sus vidas en una referencia espontánea a ciertas exigencias de comportamiento o normas de adaptabilidad. La interrogación sobre el sentido vital de estos comportamientos o de estas normas, aun si ella no sustituye directamente a la física y la química, forma parte de la biología. Como lo ha destacado Marjorie Grene, existe un lugar en la biología -junto a los bioquímicos-para un Buytendijk o un Kurt Golstein. La historia de la biología permite acordarlo (Canguilhem 2000: 138).

En síntesis, para el periodo inicial de las investigaciones de Canguilhem, la comprensión de la individualidad humana discierne dos ámbitos fundamentales. En primer lugar, ella designa un indivisible referido al individuo, destaca por su vertiente no negativa, contraria a lo que sugiere la expresión latina de individuum, que designa un ser mínimo, evanescente, un mínimo de ser. La noción de individuum para Canguilhem conlleva un sentido positivo. A la escala en que este individuo desee ser considerado, su posición será la de un "centro," centro que la vida le asigna en un lugar que no será nunca la de un objeto. En segundo lugar, este centro "subjetivo" es el que estructura el medio con el cual entra en relación y debate. La vida se manifiesta en la actividad de este centro como un principio dinámico de rebasamiento de sí mismo. El ser viviente se caracteriza por ser un ser significativo, y su individualidad, no podría ser comprendida por fuera del 
orden de los valores. Entre las ideas relativas a un ser significativo y una individualidad que rechaza toda objetivación, vivir se convierte en una forma de proyección vital, a partir de un centro de referencia, que no puede ser localizado sin perder su significación original. En la pérdida de las significaciones originales que unen al individuo con la vida, se encuentran concentradas las asignaciones de sentido que le son esenciales para significar su existencia (dimensión ontológica). Al mismo tiempo, su condición de ser significativo le brinda las potencialidades para asir una idea de valor y de norma por fuera de todo registro que no le sea íntimo y personal (dimensión ética). Las facetas del conocimiento humano quedan por ello amparadas en una concepción general del mundo y de los objetos, indisociable de la individualidad que el hombre delimita en toda actividad cognoscible (dimensión gnoseológica).

\section{El psicoanálisis no es una psicología; su posición supera la servidumbre ante los hechos}

Las críticas dirigidas por parte de Canguilhem a la psicología como al resto de las disciplinas sociales consignan en una posición distinta a los desarrollos psicoanalíticos. Esto, aun si las referencias a Freud son escasas e indirectas en el modo en que ellas son incorporadas a un cuerpo conceptual en construcción. Después de los planteamientos de 1943 relativos a lo normal y lo patológico, la situación no diferirá en lo esencial, destacándose la citación de Freud en el artículo redactado para la Encyclopedia Universalis (Canguilhem 1973:764-769). En un artículo escrito en 1929, y que lleva por título; "À la gloire de Hipocrate; père du temperament”, se encuentran los primeros alcances referidos a Freud.

Yo no pienso que el método psicoanalítico propuesto de manera posterior a Freud por el doctor Allendy, sea menos que los virus, las vacunas, los sueros, y las toxinas, un artificio verbal. No es fácil para el psicoanalista no albergar la pregunta en la respuesta o no realizar la pregunta según la respuesta que se desearía. La crítica de la medicina analítica no es un artificio verbal y es lo que importa. Es todo el hombre lo que es preciso salvar, y esto no se logra por medio de comprimidos o por parches. Suscitar el pensamiento en el hombre para que ensanche su vida orgánica y la ligue al universo según la percepción y el ardor, equivaldría quizás a curarlo o protegerlo de mejor manera. ¿Qué médico desearía decir, pero por una buena razón: nosotros hemos cambiado todo esto? (Canguilhem 2011: 251).

Estos breves alcances, destacan nuevamente la dirección de las preocupaciones de Canguilhem para estos años. Se trata indudablemente de la problemática del individuo, de su autonomía y su libertad. El texto comienza destacando la emergencia subjetiva aportada por el individuo al dominio de la ciencia, distinguiendo las preocupaciones propias de una teoría de la individualidad humana de aquellas en las cuales podría centrarse una filosofía ansiosa de generalidades. "L'individu menace la médicine" dirá Canguilhem, para de ese modo ubicar en un contexto de contrastes la posición que la categoría de individuo hace ingresar al interior del entendimiento de las enfermedades. En este texto de 1929, las expresiones de "analítico" y "sintético" emergen para evidenciar 
el estado de las distancias entre aquella medicina que incorpora la variable subjetiva, de aquella que la rechaza en la aspiración a generalidades abstractas. La división entre una medicina analítica y una medicina sintética es expuesta por Canguilhem, acorde a los postulados formulados por Allendy en su texto Orientation des idées médicales (1929). Por una parte, una medicina orientada a los "accidentes" de la enfermedad, sobrevenidos al modo de agentes externos, manifestando la presencia de una causa que puede ser localizada y circunscrita. Por otra parte, una medicina que se despreocupa de los fenómenos desencadenadores, de su aparición y su desaparición en el tiempo y el espacio. En el marco de la tradición hipocrática, lo que importa para este tipo de medicina es el desarrollo total del organismo viviente. La enfermedad puede devenir así, la traducción de la historia de un ser viviente; "la maladie devient la malade" (Canguilhem 2011: 249). Las expresiones -tempranas en la obra de Canguilhem-que se esfuerzan por traslucir la problemática relativa a la individualidad reciben en este texto de 1929 las locuciones de "sujeto," de "individualidad propia".

Por otra parte, lo que cuenta no es el fenómeno, limitado en su aparición y desaparición al tiempo y el espacio, sino el desarrollo total del organismo viviente. La enfermedad se convierte en la traducción de la historia de un ser viviente. La enfermedad resulta el enfermo. ¿Cual de los dos se encuentra más cerca del saber del médico, que transporta de un sujeto a otro las causas del mal sin tomar en cuenta al sujeto, y que les atribuye de algún modo, un poder absoluto? O del medico, que ve en el enfermo -como individualidad propia-el elemento especifico de la afección, de preferencia al microbio o a cualquier causa accidental (Canguilhem 2011: 249).

En su interés por la enfermedad y por el psicoanálisis, Canguilhem se ubica en las antípodas de lo que da en llamar el interés de los biólogos por determinar entidades puramente imaginarias. Estas entidades son abstracciones casi escolásticas, como los virus y las antitoxinas. Del lado del enfermo, el psicoanálisis es ubicado en la tradición de la práctica hipocrática de la medicina, centrada en los humores del hombre antes que en la determinación de gérmenes y microbios. Para 1929, el psicoanálisis es considerado una práctica que observa en el enfermo una individualidad propia. La teoría de Freud lejos se encuentra de ser un mero artificio verbal, evidenciando una doble preocupación por la individualidad. Por un lado, ella expresa un interés por esta individualidad en la dimensión de lo viviente, tomando al hombre como cualquier otro tipo de animal. Sin omitir por otra parte lo que él atesora de más humano; su espíritu, su personalidad. La acepción de espiritual no refiere aquí una significación de carácter metafísico, ella traduce para estos años una preocupación por los "valores humanos". Un valor orientado a destacar la "valía espíritu", en tanto producción humana no fetichizada en "valores de objeto". Una acción de valor que sea capaz de extender la vida orgánica al conjunto de los procesos que permiten la organización y regulación de lo viviente.

Estas preliminares aproximaciones al psicoanálisis connotan un interés por verlo actuar como la "psicología" necesaria a efectos de pensar lo viviente. La dimensión psíquica no puede ser con ello olvidada si se trata de pensar en las variantes que posicionan la idea de individualidad. Al interior de esta" filosofía de la vida" en 
construcción, el psicoanálisis puede orientar no solamente una psicología, pues este delinea un programa que contribuye a perfilar un tipo de política para la vida. Las tesis éticas y ontológicas necesarias para generar este programa de indagaciones políticas, Canguilhem las observa en la utilidad de las hipótesis psicoanalíticas. Aunque en un futuro no se observará de parte de Canguilhem un texto centrado en las teorías de Freud relativas a la vida pulsional, las tópicas pulsionales trabajadas por este último prestan una extrema congruencia a la definición que, para estos años, Canguilhem intenta formular para considerar la individualidad. En efecto, en lo concerniente al hombre, Canguilhem expresa la relevancia de la condición animal que lo acompaña, pero no olvida la dimensión humana que trabaja sobre los modos de tramitación de esta condición. El viviente humano puede ser considerado como un animal entre otros, pero lo que es llamado "espiritual" en 1929, insiste sobre los modos propios que este animal posee para tramitar sus inclinaciones y tendencias. Aquello que indudablemente Canguilhem define como su "personalidad", su modo particular de dirigirse a la vida y al medio circundante.

Junto al psicoanálisis, y en la intención de estructurar una nueva tonalidad comprensiva para la individualidad, la filosofía de Nietzsche se torna un centro de referencia importante. Apoyándose en una lectura de La genealogía de la moral (1997), las indagaciones sobre la filosofía de la medicina revelan un interés aún mantenido por los problemas ontológicos y éticos referidos a la individualidad. La dimensión ontológica guía en un plano general la consideración de un individuo que es visto esta vez, en razón de una (des)subtancialización; condición que afirma su normatividad como una capacidad sin medida posible. Normatividad que crea y dirige una acción que se instituye en una relación de fuerzas que atraviesan al individuo. En el sentido que inaugura esta nueva perspectiva relativa al individuo, la salud es entendida como un riesgo afirmado y asumido por el sujeto. Este individuo debe entonces rebasar sus límites para abrirse a nuevos horizontes. La dimensión ética se perfila en la moral del riesgo, opuesta a toda moral del equilibrio y la conservación.

En una moral que es ahora del riesgo y del error, el psicoanálisis surge para rechazar una moral del equilibrio y la conservación. La utilidad del psicoanálisis para la construcción de una ética que es igualmente una política, se introduce mediante la consideración de una vida que no puede ser pensada sin la presencia de la muerte. Si la expresión para pensar esta nueva situación del individuo es la de la normatividad, el psicoanálisis es la herramienta que permite pensar cómo una filosofía de la vida puede ser aprehendida como una verdadera política de lo viviente.

Considerada del punto de vista del enfermo, la muerte es un limite inscrito en su patrimonio genético, como si su destrucción y retorno a la inercia pasado un cierto plazo, le fuera impuesta como su último deber. Se podría preguntar entonces, ¿por qué una teoría como la que Freud esquematizó bajo la apelación de "pulsión de muerte," encontró tanta resistencia? Esta idea se encontraba ligada en Freud a una consideración energética de la vida y del psiquismo. Ahora bien, si es verdad que el viviente es un sistema en desequilibrio incesantemente compensado por sus préstamos con el exterior, si es verdad que la vida se encuentra en tensión con el medio inerte, ¿qué hay de extraño o de contradictorio en la hipótesis de 
un instinto de reducción de las tensiones a cero, de una tendencia a la muerte? (Canguilhem 1973: 769).

Es la dimensión ética y ontológica la que destaca en las referencias al psicoanálisis de Freud, para una moral que no respeta ningún tipo de orden preestablecido. Estas dimensiones, se convierten expresamente en inquietudes de un amplio tenor político como se lee en 1978.

Las enfermedades del hombre no son solamente limitaciones de su poder físico, son dramas de su historia. La vida humana es una existencia, un ser allí para un devenir no pre-ordenado en la idea aterradora de su fin. El hombre se encuentra abierto a la enfermedad, no por una condena o por un destino, sino por su simple presencia en el mundo. Bajo esta relación, la salud no es de ningún modo una exigencia de orden económico a hacer valer en el marco de una legislación, ella es una unidad espontánea de las condiciones de ejercicio de la vida (Canguilhem 2002: 89).

Esta "presencia en el mundo" que vincula al hombre con las diversas figuras de la enfermedad hace de la salud, una verdad del cuerpo. Verdad que como una expresión de la "especificidad" de lo viviente, es ontológica en lo que ella muestra de esencial para la existencia del individuo. Pero es esa misma verdad la que permite retornar a los aspectos del "buen vivir", a una ética de lo viviente. Vivir acorde a normas y valores es una forma de expresar las resistencias que el organismo estructura frente a las leyes de degradación de la vida, su capacidad de expresar frente a esta degradación, las posibilidades de rebasar sus creaciones y normatividades. Lo que el organismo expone frente al mundo, es la manera que posee de realizarse a sí mismo. Por lo tanto, un cuerpo no podría ser nunca un simple objeto. Es en torno de estas ideas referidas a una filosofía de la medicina, donde la articulación de la dimensión ética, ontológica y gnoseológica, puede ser apreciada.

El cuerpo vivido no es un objeto, para el hombre vivir es también conocer. Yo me comporto bien en la medida en que me siento capaz de conducir la responsabilidad de mis actos, de llevar las cosas a la existencia y de crear entre las cosas, relaciones que no podrían acontecer sin mí, pero que no serían lo que son sin ellas. Entonces, tengo la necesidad de aprender a conocer lo que ellas son para cambiarlas (Canguilhem 2002: 68).

\section{Conclusión}

Para Canguilhem, una filosofía de la autonomía y la acción humana se orienta a la consideración de todo lo que en el individuo se expresa como un acto de existencia. Forma de expresión de una "dinámica de los posibles," donde se asienta una idea de acción, de responsabilidad y creación. La consideración de la noción de individuo permanece ligada al territorio de esta responsabilidad, compromiso que es también una forma de vinculación a los objetos y a su conocimiento. Es en el desarrollo de este conocer donde el individuo se realiza a sí mismo. En estas argumentaciones que permanentemente 
vinculan aspectos éticos, ontológicos y gnoseológicos, Canguilhem intenta ubicar la relevancia del psicoanálisis como disciplina. La teoría freudiana no es tomada como la psicología ausente y necesaria para un programa filosófico referido a lo viviente y sus acciones. El psicoanálisis interesa por la política de la vida que involucra en sus principios, es así al menos como surgen las escasas citas que Canguilhem desarrolla a propósito de Freud. Esa política es la que define, pero al mismo tiempo integra, las dimensiones éticas, ontológicas y gnoseológicas referidas al viviente humano. El psicoanálisis permite la trasformación conceptual que intenta ser operada para el individuo; desalojarlo de la facticidad en que las ciencias lo sumergen, para destacar una incompletud que se torna política en sus alcances.

\section{Referencias bibliográficas}

Avery, Oswald. Macleod, Colin (1944), "Studies on the Chemical Nature of the Substance Inducing Transformation of Pneumococcal Types: Induction of Transformation by a Desoxyribonucleic Acid Fraction Isolated from Pneumococcus Type". Journal of Experimental Medicine 79 (2): 137-158.

Allendy, René (1929), L'Orientation des idées médicales. Paris: Editions au Sans Pareil.

Alain (1960), Mars ou la guerre jugée, Les passions et la sagesse. Paris: Gallimard.

Bergson, Henry (2009), La pensée et le mouvement. Paris: P.U.F.

Braunstein, Jean F. (2000), "Canguilhem avant Canguilhem”. Revue d'Histoire des sciences, Année 2000, 53-1: 9-26.

Canguilhem, Georges (2011), Écrits philosophiques et politiques (1926-1939). Paris: Vrin.

(2002), Ecrits sur la médecine. Paris: Seuil.

(2000), Idéologie et rationalité dans l'histoire des sciences de la vie.

Paris: Vrin.

(1992), La connaissance de la vie. Paris: Vrin.

(1973), "Vie". Encyclopaedia Universalis, tome 16. Paris; pp. 764-769.

(1966), Le normal et le pathologique. Paris: P.U.F.

(1962), Du développement à l'évolution au XIXe siècle. Paris: P.U.F.

Foucault, Michel (2011), Dits et écrits II (1976-1988). Paris: Essais-Gallimard.

Halbwachs, Maurice (1930), Les causes du suicide. Paris: Librairie Félix Alcan.

Kant, Immanuel (2000), Critique de la faculté de juger. Paris: Flammarion.

Lecourt, Dominique (2008), Georges Canguilhem. Paris: P.U.F.

Nietzsche, Friedrich (1997), Généalogie de la morale. Paris: Flammarion.

Politzer, Georges (1968), Critique des fondements de la psychologie. Paris: P.U.F.

Simondon, Gilbert (2005), L'individuation à la lumière des notions de forme et d'information. Paris: Million. 